\title{
Effect of Strengthening on the Fatigue Life of Construction Materials
}

\author{
Karol Brzeziński1 ${ }^{1 *}$ Artur Zbiciak ${ }^{1}$ Andrzej Garbacz² \\ 1 Institute of Roads and Bridges, Faculty of Civil Engineering, \\ Warsaw University of Technology, Armii Ludowej 16, 00-637 Warszawa \\ 2 Institute of Building Engineering, \\ Warsaw University of Technology, Armii Ludowej 16, 00-637 Warszawa \\ *Corresponding author, e-mail: k.brzezinski@il.pw.edu.pl
}

Received: 18 July 2018, Accepted: 06 January 2019, Published online: 04 February 2019

\begin{abstract}
The paper describes a new method for assessing the impact of increasing static strength due to cyclic loading on the fatigue life of various materials and provides a mathematical description. Experimental results available in the literature were used. A generalized concept of unit fatigue damage was used to produce a simple hypothesis defining fatigue life as a function of load history. The method is mainly devoted to analysis of semi-rigid asphalt pavements but can also be applied to other engineering materials. Two sample calculations were conducted which drew on the results of fatigue tests under variable loading: one concerns cement-treated soils used as base layers for road pavements and the second describes the fatigue problem of a beam rear axle made of TL1114.
\end{abstract}

\section{Keywords}

fatigue life, cement-treated base layers, fatigue hypothesis, load history, semi-rigid pavements

\section{Introduction}

Many fields of engineering, especially civil engineering and the automotive industry, are searching for a more accurate way of predicting the fatigue life of materials and structures. For example, as regards asphalt pavement design the most universal methods [1, 2] are mechanistic-empirical methods. Their application requires the calculation of stress and strain conditions at critical points under the influence of expected loads. On the basis of these calculations, the fatigue life can be estimated by means of empirically established formulas. Two basic criteria are applied. The first concerns the cracks on the bottom of asphalt layers caused by repetitive loads produced by wheels of vehicles. The second criterion refers to the phenomenon of structural rutting, the result of accumulation of irreversible deformations in the upper layers of the soil subgrade. In the case of semi-rigid pavements, the structural damage process is subdivided into two stages, i.e. before and after the occurrence of fatigue cracks.

If the amplitude of cyclic loading is constant, the Palmgren-Miner Rule is usually sufficiently accurate to predict the fatigue life. The formula describing the fatigue failure condition based on the PMR is as follows [3]: $\sum_{i=1}^{m} \frac{n_{i}}{N_{i}}=1$,

where:

- $n_{i}$ - number of cycles at stress level $\sigma_{i}$,

- $N_{i}$ - number of cycles inducting failure at stress level $\sigma_{i}$,

- $m$ - number of stress levels $\sigma_{i}$.

Numerous research results show the significant effect of load history on fatigue life, which is not included in the PMR. This phenomenon was observed in the case of metallic $[4,5]$, cement concretes [6], and cement treated soils [7]. Therefore, several hypotheses aiming to estimate the fatigue life of the structure under variable loads have been posited, including modified Miner's rule (MMR) and relative Miner's rule (RMR). The phenomenon of fatigue is described more and more accurately, for example, by the description as a stochastic process $[8,9,10]$. High accuracy may be obtained by taking into account the strengthening effect of load cycles below the fatigue limit (LALS). The strengthening effect in this case is understood as an increase in fatigue strength. It can be determined by performing additional fatigue tests of samples pre-loaded with a small amplitude load. In the present work the strengthening effect 
is also taken into account, but defined as an increase in the static strength. Various studies show that cyclic loading can cause an increase in static strength: e.g. yield stress in the case of metallic alloys [11] and the flexural strength of cement-treated soils [7, 12]. This phenomenon can be explained by the dislocations motion, the self-arrangement of the materials internal micro-structure or fracture toughness increasing by micro-cracks [13]. The dislocations motion can be observed in abovementioned materials. For example in cement-based materials the motion of charged dislocations indicates electric current in loaded specimens [14]. The strengthening effect has led to the development of a new method for estimating the fatigue life of cement treated soils under variable amplitude loads. The hypothesis presented in this paper has been already published in Polish with the example calculation for samples of cement treated soils [15]. At the beginning of this paper we briefly present the assumptions of the hypothesis with results of primary case. Later we show that this method may be utilized in other industry branches like an automotive industry. Finally we also present possible application in pavement design process. Experimental results available in the literature were used. A generalized concept of unit fatigue damage allowed the formulation of a simple hypothesis defining fatigue life as a function of load history.

\section{Generalized unitary fatigue damage (GUFD) concept 2.1 Basic assumptions}

In order to use the PMR the relationship between the level of load and fatigue life (S-N curve) obtained as a result of tests at constant amplitude cyclic loading is required. The complete fatigue tests are time-consuming and expensive. Thus, the relationships between fatigue strength and physical or mechanical properties are investigated. Such mechanical properties can be easily measured. An example of this kind of relationship is the Illinois criterion, applied for cement-treated mixtures and described by the following formula [16]:

$\log N_{k}=11.784-12.121(S)$

where:

- $N_{k}$ - allowable number of load repetitions,

- $S$ - applied flexural stress/flexural strength ratio.

The results obtained using the Illinois criterion are not as accurate as in the case of curves constructed on the basis of individual fatigue tests. However, this criterion shows how important the degree of effort in the structure under cyclic loads is. Thus, a relation between the load and the static strength can be a reference point for the comparison of materials with different properties. Further evolution of this idea is a concept of the change in the static strength of the material under cyclic loading [15].

The results of research presented by Koba [7], related to cement-treated soils, illustrate the importance of the sequence of variable load amplitudes. As proved by Koba, specimens subjected to pre-loading demonstrated much greater fatigue life than could be obtained with the PMR. In addition, the samples which were not destroyed by cyclic loading showed an increase in static strength compared with samples not subjected to pre-loading.

Combining these observations allowed the adoption of two assumptions, leading to the development of a new method for determining fatigue life by taking into account the effect of changes in static strength [15].

Assumption No. 1. Static strength of material may increase as a result of cyclic loading.

The phenomenon of increasing static strength of cementtreated soils owed to cyclic loads is not fully described in the literature. In this paper the simplified function of the static strength increase was established from indirect observations.

Assumption No. 2. The material under a single load cycle experiences loss of fatigue life, depending on the updated effort (stress) ratio, i.e. the ratio of load to updated static strength.

The acknowledged consequence of both assumptions is that, because of the increase in updated static strength with a constant load, the fatigue damage will grow non-uniformly because the updated stress ratio of the sample decreases. This is the fundamental difference between the method proposed in our paper and the classical approach (e.g. the Illinois criterion), where the linear fatigue damage during the whole process of destruction is assumed.

\subsection{Description of the method}

The phenomenon of increase in the static strength of the material as a result of cyclic loading observed by Koba [7] has largely been reported in relation to metallic alloys. Some papers emphasize the effect of this phenomenon on fatigue life $[4,5,17]$. However, the strengthening effect has so far been observed only through a direct increase in fatigue strength. In contrast, a completely new approach is proposed in this paper. It consists of the calculation of an increase in fatigue strength by taking into account the changes in the static strength of the material under cyclic loading. In order to explain the principles set out in Section 2.1, the following parameters are used: 
- $R_{u}$ - updated static strength - static strength of material subjected to a certain number of load cycles,

- $R_{n}$ - nominal static strength - static strength of material before any cyclic loading,

- $S_{n}$ - nominal stress ratio, ratio of load to nominal static strength $R_{n}$,

- $S_{u}$ - updated stress ratio, ratio of load to updated static strength $R_{u}$,

- $d$ - generalized unitary fatigue damage - loss of the structure fatigue life under a single load cycle. It should be emphasized that in the case of the PMR, which does not take into account the increase in updated static strength, the unit fatigue damage is constant $d=1 / N$, where:

- $N$ - number of load repetitions to failure.

Assumption No. 1 above refers to static strength. It was observed, that depending on the nominal stress ratio and the number of loads, the static strength may change in different ways [11]. The same applies to changes in the fatigue strength of pre-loaded specimens $[4,5]$. In this paper we assume that the static strength changes as shown in Fig. 1. It should be emphasized that our approach differs from that presented by Xi and colleagues [4] where the curve shown in Fig. 1 relates to the fatigue strength.

Because of the lack of sufficiently accurate research in this area, some simplifications have been made. It has been assumed that the increase in the static strength depends only on the number of cycles and the strengthening function corresponds to the optimal nominal stress ratio. Assumption No. 2 above introduces a slight but significant modification to the method previously used. Usually, the fatigue life is determined as a function of the nominal stress ratio, assuming that during the constant amplitude loading stress ratio does not change. However, taking into account Assumption No. 1 (the strengthening of the material) naturally creates the need for a formula containing updated stress ratio $S_{u}$. Therefore, the generalized unit fatigue damage (GUFD) concept has been used in order to describe the phenomenon of the fatigue, allowing us to take into account the above assumptions.

The curve representing the PMR in Fig. 2 is actually a constant function, because the stress ratio does not change during loading. Consequently, it is not necessary to consider any unit fatigue damage in this case. Of course, taking into account the effect of strengthening should not alter the fatigue curves, previously calibrated in the conventional manner. Such a procedure would lead to an underestimation of the value of the function of unit fatigue damage.

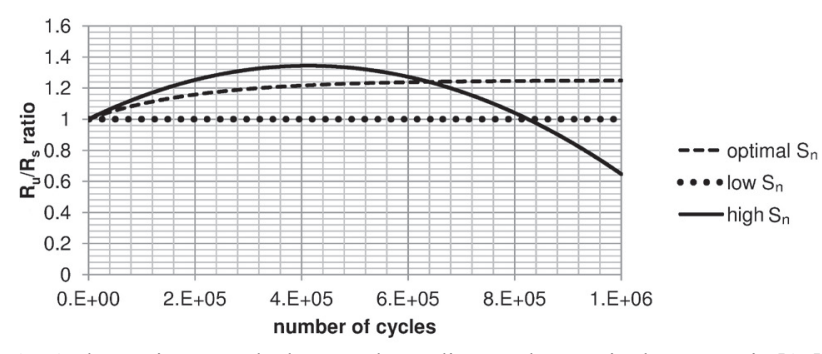

Fig. 1 The static strength changes depending on the nominal stress ratio [15]

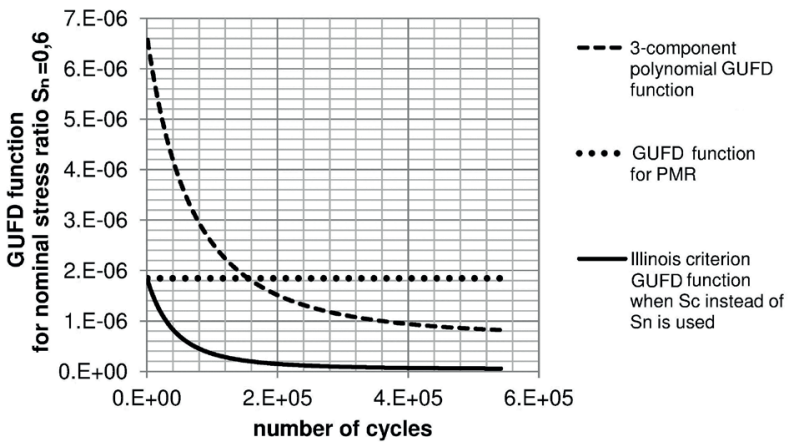

Fig. 2 The change in generalized unitary fatigue damage in the process of cyclic loading [15]

Thus, the cumulated fatigue damage would also be underestimated. It is therefore necessary to calibrate a new curve or to propose a function directly describing the unit fatigue damage. Then the total fatigue damage can be determined as the cumulative sum or the integral of the function of unit damage. As the sample calculation will show, the approach takes into account the loading history, which has a significant impact on improving the estimation of fatigue life.

\section{Validations}

In order to verify the potential suitability of the method, two sample calculations were performed in different fields of engineering: civil engineering and the automotive industry.

\subsection{Constant amplitude loading: cement treated soil}

Before attempting to verify the potential suitability of the method by the sample calculation, the relationship between the unit fatigue damage and the updated stress ratio needs to be established. The research conducted by Koba [7] using specimens of cement treated silty sand at different levels of load and established the following fatigue curve ( $\mathrm{S}-\mathrm{N}$ curve):

$\log N_{k}=13.7801-13.4102(S)$.

Thus, the equation of generalized unit fatigue damage in the case of the above curve is as follows:

$d_{1}=\frac{1}{10^{13.7801-13.4102 \cdot S_{n}}}$. 
Similarly, in the case of the Illinois criterion, the GUFD function has the following form:

$$
d_{2}=\frac{1}{10^{11.784-12 \cdot 121 \cdot S_{n}}} .
$$

Since the Illinois criterion and the experimental curve are not intended to take into account the increase of static strength, the updated stress ratio does not change and is equal to the nominal stress ratio.

The proper function of the GUFD with respect to the presented method has been presented in the form of polynomial curves:

$$
\begin{aligned}
& d_{3}=a_{1} \cdot S_{u}^{\alpha}+a_{2} \cdot S_{u}^{\beta}+a_{3} \cdot S_{u}^{\gamma}, \\
& d_{4}=a_{1} \cdot S_{u}^{\alpha}+a_{2} \cdot S_{u}^{\beta},
\end{aligned}
$$

where $\alpha, \beta, \gamma$ are the polynomial coefficients and are the exponent parameters. The increase of strength is described by Eq. (8), depending on the number of loading cycles $i$.

$\frac{R_{u}}{R_{n}}=\frac{S_{n}}{S_{u}}=1+A \cdot\left(1-e^{\frac{-i}{C}}\right)$,

where $A=0.25$ is the maximum increase in the static strength after $C=200000$ of loading cycles. This formula corresponds to the previously discussed case of strengthening material at the optimal $S_{n}$. The constants $A$ and $C$ were assumed on the basis of observations of Koba [7].

As a result of the calibration procedure the parameters of the investigated GUFD functions were obtained and are shown in Table 1. The GUFD functions are illustrated in Fig. 3.

Table 1 Parameters of the proposed function of the generalized unit fatigue damage: cement-treated soils

\begin{tabular}{lcccccc}
\hline Param. & $\alpha$ & $\beta$ & $\gamma$ & $a_{1}$ & $a_{2}$ & $a_{3}$ \\
\hline$d_{3}$ & 25.85 & 9.65 & 58.52 & 0.256 & $8.6 \mathrm{e}-4$ & 0.733 \\
$d_{4}$ & 27.51 & 9.92 & - & 0.366 & 0.001 & - \\
\hline
\end{tabular}

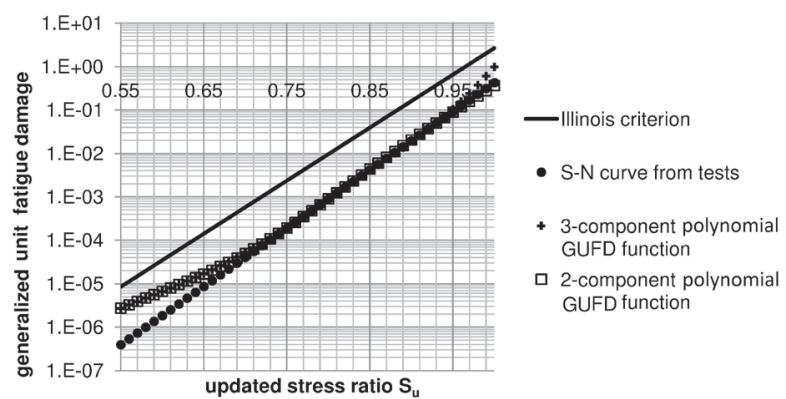

Fig. 3 Selected functions of generalized unit fatigue damage depending on updated stress ratio [15]
Table 2 Results of the predicted fatigue life N, calculated with the experimental S-N curve and the proposed GUFD functions:

cement-treated soil samples

\begin{tabular}{lccc}
\hline$S_{n}$ & $N($ S-N curve $)$ & $N\left(d_{3}\right)$ & $N\left(d_{4}\right)$ \\
\hline 0.55 & 2537990 & 2620320 & 2484285 \\
0.60 & 541976 & 515959 & 505306 \\
0.65 & 115736 & 121749 & 119423 \\
0.70 & 24711 & 25430 & 23810 \\
0.75 & 5277 & 5324 & 4983 \\
0.80 & 1127 & 1125 & 1123 \\
0.85 & 240 & 233 & 252 \\
0.90 & 51 & 48 & 53 \\
0.95 & 10 & 10 & 9 \\
\hline
\end{tabular}

Table 3 One-day pre-load: cement-treated soil samples

\begin{tabular}{lc} 
Nominal stress ratio $S_{n}$ & Number of cycles $N$ \\
\hline 0.55 & 20250 \\
0.60 & 6000 \\
0.65 & 2000 \\
0.70 & 1000 \\
0.75 & 500 \\
0.55 & 20250 \\
\hline
\end{tabular}

The most salient feature of the calibrated polynomial functions is that they significantly differ from fatigue damage determined from the classic S-N curve at low updated stress ratio. This is because the strengthening of the material needs many loads to be repeated. This phenomenon reduces the updated stress ratio. However, since the target fatigue life is the same regardless of the method (test results), the consequent fatigue damage must be greater with a lower updated stress ratio.

Comparison of the results of fatigue life $\mathrm{N}$, calculated with the experimental S-N curve and the proposed GUFD functions, shows the calibration is good in the case of fixed nominal stress ratio (see Table 2).

It should be emphasized that the essence of the proposed method is not only matching the results under constant amplitude load but taking into account the history of variable amplitude loads. Therefore, the calibrated functions are used in the sample calculation in which the results drastically differ from predictions by PMR.

\subsection{Variable amplitude loading: cement-treated soil}

The results of the fatigue tests of cement-treated soils under variable load amplitude were analyzed. The applied load program included the actual distributions of pressure on the road surfaces from different vehicles. The samples 
were pre-loaded for 28 days. The one-day pre-load cycle is shown in Table 3. Both fatigue and strength tests were performed on a four-point bending test machine. A detailed description of the test was given by Koba [7].

After the initial loading, the samples were loaded in blocks of 500 cycles. The updated stress ratio in each subsequent block was increased by 0.05 of $R_{n}$.

The effect of the strengthening phenomenon was unexpected. The specimens were destroyed after 283 cycles at very high nominal stress ratio $S_{n}=1.15$. With this strengthening effect it is not possible to estimate the fatigue damage by using the PMR. Therefore, comparison of the results is presented up to the point where the load was at nominal stress ratio $S_{n}=0.95$, and the fatigue damage obtained using the PMR was greater than 60 (a typical failure condition equals one).

The calculations were performed with the use of the above GUFD Eq. (6) and (7), and the total fatigue damage was determined by the following formula:

$D_{j}=\sum_{i=1}^{N} d_{j}\left(S_{u}\right)_{i}$.

The effect of growth of the fatigue damage calculated with both the GUFD concept $\left(D_{4}\right)$ and the Palmgren-Miner Rule $\left(D_{1}\right)$ is shown in Fig. 4.

Finally, the cumulative fatigue damage, calculated until the nominal stress ratio $S_{n}=0.95$, for the fourth function of unit damage fatigue was $D_{4}=1.32$. In the case of the first function, when strength changes were not taken into account, the cumulative fatigue damage was $D_{1}=62.95$.

\subsection{Constant amplitude loading: torsion beam rear axle}

The second example concerns the calculation of fatigue tests for a vehicle element. A description of the research has been presented in detail by Zhao and colleagues [5]. They analyze the obtained results using various fatigue hypotheses. They also propose a new method for fatigue life prediction under service loading histories by taking into account

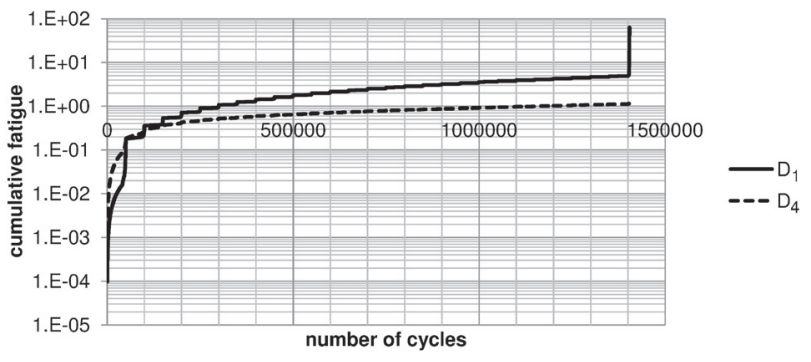

Fig. 4 Growth of the fatigue damage calculated with the GUFD concept (D4) and Palmgren-Miner Rule (D1) low-amplitude-load strengthening (LALS). The main assumption of the aforementioned method is that the fatigue strength of materials increases because of pre-loading under low amplitude (65\% to $95 \%$ of fatigue limit). The following shows the results obtained for the beam rear axle, as well as a comparison with the results of calculations performed with the method presented in this paper.

The S-N curve determined under constant amplitude loading can be expressed as [5]:

$\log N_{k}=18.0942-6.1538 \cdot\left(S_{a}\right)$,

where $S_{a}$ is stress level [MPa]. Further calculations were carried out with the nominal static strength $R_{n}=360 \mathrm{MPa}$ equal to the yield strength. The next step of the procedure needs the function of the static strength growth to be assumed. As in the previous example the updated static strength is expressed by Eq. (8). The coefficients used in the model were obtained from the literature $[4,10]$. Therefore, it was assumed that the yield strength increases up to $A=0.11$ during $C=200000$ cycles of loading. The fatigue unit damage $d_{5}$ was determined by Eq. (7). The calibration results are shown in Tables 4 and 5 .

Table 4 The parameters of the proposed function of the generalized unit fatigue damage: torsion beam rear axle

\begin{tabular}{lcccc}
\hline Param. & $\alpha$ & $\beta$ & $a_{1}$ & $a_{2}$ \\
\hline$d_{5}$ & 3.14 & 6.23 & $4.93 \mathrm{e}-5$ & $4.35 \mathrm{e}-3$ \\
\hline
\end{tabular}

Table 5 Results of the predicted fatigue life N, calculated with the experimental S-N curve and the proposed GUFD functions: cementtreated soil samples

\begin{tabular}{lcccc}
\hline$S_{a}[\mathrm{MPa}]$ & $R_{n}[\mathrm{MPa}]$ & $S_{n}$ & $N(\mathrm{~S}-\mathrm{N}$ curve $)$ & $N\left(d_{5}\right)$ \\
\hline 101.0 & 360 & 0.28 & 575226 & 569129 \\
130.0 & 360 & 0.36 & 121695 & 121810 \\
159.0 & 360 & 0.44 & 35245 & 35160 \\
188.0 & 360 & 0.52 & 12570 & 12672 \\
216.5 & 360 & 0.60 & 5274 & 5287 \\
\hline
\end{tabular}

Table 6 Block loading of rear axle [5]

\begin{tabular}{lcc}
\hline$S_{a}[\mathrm{MPa}]$ & $S_{n}$ & Number of cycles $N$ \\
\hline 14.5 & 0.04 & 3708 \\
43.5 & 0.12 & 1652 \\
72.0 & 0.20 & 441 \\
101.0 & 0.28 & 121 \\
130.0 & 0.36 & 24 \\
159.0 & 0.44 & 22 \\
188.0 & 0.52 & 8 \\
216.5 & 0.60 & 5 \\
\hline
\end{tabular}


Table 7 Comparison of results of the fatigue life test and calculations conducted with different methods

\begin{tabular}{lccccc}
\hline \multirow{2}{*}{ Damage model } & PMR & \multicolumn{2}{c}{ MMR } & LALS & GUFD \\
& & $\mathrm{k}^{\prime}=\mathrm{k}-1$ & $\mathrm{k}^{\prime}=2 \mathrm{k}-1$ & \\
\hline average test life (blocks) & 510 & & & & \\
predicted life (blocks) & 382 & 367 & 375 & 501 & 432 \\
error [\%] & 25.1 & 28.0 & 26.5 & 1.8 & 15.3 \\
\hline
\end{tabular}

\subsection{Variable amplitude loading: torsion beam rear axle}

The variable loads were applied in the form of an eightlevel loading block [5]. The levels of loading and corresponding numbers of cycles are shown in Table 6. The loading blocks were repeated until failure.

The test results and the fatigue life calculations conducted by Zhao and colleagues [5] were compared with the prediction obtained by using the GUFD concept (Table 7). The slope of S-N curve extension in modified Miner's rule is denoted $\mathrm{k}^{\prime}$.

\section{Practical application}

Pavement structure constantly operates under variable loads depending on the vehicle types and weather conditions. This is stochastic process, so the example application of presented method taking into account this kind of variability would not be clear enough. However there are some cases where mean amplitude of the load changes instantly and then remains constant for longer period of time. This is during construction of the road or after pavement repair when additional asphalt layer is placed.

The tension stress on the bottom of example pavement structure (Table 8) was calculated under $40 \mathrm{kN}$ wheel load. Assuming that nominal flexural strength of cement treated mixture in subbase is $R_{n}=1.20 \mathrm{MPa}$ we can find that nominal stress ratio $S_{n}$ could vary between 0,95 (when construction machines rides directly on the cement treated layer) and 0,48 (when pavement structure is finished).

Table 8 The parameters of the analyzed pavement structure

\begin{tabular}{lcccc}
\hline Layer & Material & $\begin{array}{c}\text { Youngs } \\
\text { Modulus [MPa] }\end{array}$ & $\begin{array}{c}\text { Poissons } \\
\text { ratio [-] }\end{array}$ & $\begin{array}{c}\text { Depth } \\
{[\mathrm{cm}]}\end{array}$ \\
\hline $\begin{array}{l}\text { Wearing } \\
\text { course }\end{array}$ & $\begin{array}{c}\text { Asphalt } \\
\text { concrete }\end{array}$ & 10300 & 0.30 & 4 \\
$\begin{array}{l}\text { Binding } \\
\text { course }\end{array}$ & $\begin{array}{c}\text { Asphalt } \\
\text { concrete }\end{array}$ & 10100 & 0.30 & 5 \\
$\begin{array}{l}\text { Subbase } \\
\text { Cement treated } \\
\text { mixture }\end{array}$ & 7000 & 0.25 & 18 \\
Ground & Sand & 80 & 0.30 & - \\
\hline
\end{tabular}

Table 9 Comparison of laboratory test, PMR and GUFD methods

\begin{tabular}{lcc}
\hline Damage model & Number of cycles & error [\%] \\
\hline Estimated with PMR & 22371 & 17 \\
Estimated with GUFD & 19877 & 4 \\
Laboratory [7] & 19075 & - \\
\hline
\end{tabular}

It should be noted that in this example we analyze opposite effect - the weakening material, when very high load is applied at early stages of loading. So the PMR would overestimate the fatigue life of the material. This effect also may be taken into account with GUFD method, but requires information about both positive and negative influence of the load history on the static strength of the material. This relationship was acquired from [18] for sand stabilized with $10 \%$ of cement. The fatigue tests results for similar mixture was obtained from [7]. The samples were preloaded with nominal stress ratio is $S_{n}=0.80$ for 112 times. In the next step the $S_{n}$ was reduced to 0.7 . Samples were loaded with this magnitude until destruction. Results of laboratory test, PMR and GUFD methods are compared in Table 9.

As it can be seen the GUFD concept allows for taking into account both strengthening and weakening of the material. There is no need to conduct additional fatigue tests under variable amplitude loading. However changes in static strength of the material must be assumed. So this phenomenon should be better investigated.

\section{Discussion}

In the case of cement-treated soil the results obtained with the proposed method much better reflect the assumptions of fatigue hypotheses, where the failure occurs at the cumulative damage $D=1$. However, it should be noted that our calibration was based on limited research, indirectly drawing conclusions about changes in static strength.

The second example shows that the accuracy of the proposed method is higher than that of the classical methods (PMR and MMR). On the other hand, the proposed method gives worse results than the method accounting for the LALS effect.

Greater accuracy of the LALS method is also associated with greater labor consumption because the calibration of the method requires the material fatigue characteristics to be determined twice. The first fatigue characteristic should be obtained without pre-loading but the second one needs to be calibrated after pre-loading. However, in the case of the GUFD concept [15], the fatigue characteristics are determined only once. Moreover, the specification of the static strength increase is also required, which is much less 
time-consuming. Another limitation of the LALS method is that it only takes into account the strengthening influence of the loading below the fatigue limit. Thus, in the case of variable amplitude in a range above the fatigue limit the LALS method is reduced to PMR.

Verifying the accuracy and usefulness of the method still requires a number of experiments, especially about the impact of cyclic loading on the constitutive properties of materials. Further work by the authors of this paper will focus on experimental verification of the proposed method, and examination of the impact of cyclic loading on the static strength of cement-treated soils.

\section{Conclusions}

On the basis of conducted analysis following conclusions can be drawn:

- The proposed method describes in a simple way the effect of strengthening on the fatigue life of engineering materials.

- Consequently, the changes in the updated static strength of material under cyclic loading are very important and should be determined in the laboratory. This phenomenon is not well recognized, especially in the case of cement-treated soils. Therefore, complex research is required.

- The proposed method can be applied to a variety of materials that reveal a change in updated static strength caused by cyclic loading.

\section{Acknowledgement}

Experimental results for example calculation of fatigue were obtained from literature.

This research was conducted by using the funds from Polish Government allocated to statutory aims of the Faculty of Civil Engineering.

\section{References}

[1] Judycki, J., Jaskuła, P., Pszczoła, M., Jaczewski, M., Ryś et al. "Analysis and design of semi-rigid and flexible pavement structures", 1st ed., Transport and Communication Publishers (WKŁ), Warsaw, Poland, 2014. (in Polish)

[2] Papagiannakis, A. T., Masad, E. A. "Pavement Design and Materials", 1st ed., John Wiley \& Sons, Hoboken, New Jersey USA, 2008.

[3] Miner, M. A. "Cumulative damage in fatigue", Journal of Applied Mechanics, 12, pp. 159-164, 1945. [online] Available at: https:// www.scirp.org/(S(351jmbntvnsjtlaadkposzje))/reference/ReferencesPapers.aspx?ReferenceID=1751417 [Accessed: 30.01.2019]
[4] Xi, L., Songlin, Z. "Strengthening and damaging under low-amplitude loads below the fatigue limit", International Journal of Fatigue, 31(2), pp. 341-345, 2009.

https://doi.org/10.1016/j.ijfatigue.2008.08.004

[5] Zhao, L., Zheng, S., Feng, J. "Fatigue life prediction under service load considering strengthening effect of loads below fatigue limit", Chinese Journal of Mechanical Engineering, 27(6), pp. 1178-1185, 2014.

https://doi.org/10.3901/CJME.2014.0806.130

[6] Oh, B. H. "Cumulative damage theory of concrete under variable-amplitude fatigue loadings", American Concrete Institute Materials Journal, 88(1), pp. 41-48, 1991. [online] Available at: https:/www.researchgate.net/publication/280691991_Cumulative_ damage_theory_of_concrete_under_variable-amplitude_fatigue loading [Accessed: 30.01.2019]

[7] Koba, H. "Durability of road pavements with cement-bound subbase", 1st ed., Oficyna Wydawnicza Politechniki Wrocławskiej, Warsaw, Poland, 2000. (in Polish)

[8] Pożarycki, A., Górnas, P., Fengier, J. "Pavement Fatigue Degradation Phenomenon Assessment Based on Multi-load FWD Data and Stochastic Process Evaluation", Periodica Polytechnica Civil Engineering, 60(4), pp. 471-477, 2016. https://doi.org/10.3311/PPci.7880

[9] Ying, Z., Yuji, T. "Spectral Method for Fatigue Damage Assessment of Structures with Uncertain Parameters", Periodica Polytechnica Civil Engineering 61(4), pp. 929-938, 2017. https://doi.org/10.3311/PPci.9644

[10] Macha, E. "Spectral method of fatigue life calculation under random multiaxial loading", Materials Science, 32(3), pp. 339-349, 1996. https://doi.org/10.1007/BF02539171

[11] Moćko, W., Kowalewski, Z. L. "Evolution of tensile properties of the TIAL6V4 alloy due to the prior cyclic loading history", Journal of Theoretical and Applied Mechanics, 52(3), pp. 847-851, 2014. [online] Available at: http://www.ptmts.org.pl/jtam/index.php/ jtam/article/view/v52n3p847/1863 [Accessed: 30.01.2019]

[12] Brzeziński, K., Adamczewski, G., Tutka, P. "The influence of cyclic loading on the static strength of cement-bound sand-qualitative analysis", Roads and Bridges - Drogi i Mosty, 16(1) pp. 37-46, 2017.

https://doi.org/10.7409/rabdim.017.003

[13] Brzeziński, K. "XFEM simulation of introduced by pre-loading cracking influence on the strengthening of the cement treated mixture", Journal of Theoretical and Applied Mechanics, 56(4), pp. 927-938, 2018.

https://doi.org/10.15632/jtam-pl.56.4.927

[14] Kyriazopoulos, A., Anastasiadis, C., Triantis, D., Brown, C. J. "Non-destructive evaluation of cement-based materials from pressure-stimulated electrical emission - Preliminary results", Construction and Building Materials 25(4), pp. 1980-1990, 2011. https://doi.org/10.1016/j.conbuildmat.2010.11.053

[15] Brzeziński, K., Zbiciak, A. "Influence of load history on the fatigue life of cement treated soils", Drogownictwo, 69(9), pp. 288-293, 2014. (in Polish) 
[16] Dempsey, B. J., Janssen, D., Thomas, J., Frey, P., Ioannides, A., Elliot, R. "Development of a Preliminary ALRS Stabilized Material Pavement Analysis System (SPAS)", Department of Civil Engineering, University of Illinois, Champaign, Illinois, USA, Final Rep., 1984.

[17] Li, J., Sun, Q., Zhang, Z.-P., Li, C.-W., Qiao, Y.-J. "Theoretical Estimation to the Cyclic Yield Strength and Fatigue Limit for Alloy Steels", Mechanical Research Communications, 36(3), pp. 316-321, 2009.

https://doi.org/10.1016/j.mechrescom.2008.10.011

[18] Brzeziński, K. "Evaluation of the cyclic loading influence on the static strength of the cement treated mixtures used in the construction of road pavements", PhD Thesis, Warsaw University of Technology, 2017.

\section{Appendix 1 - Workflow}

The method of prediction the fatigue life under variable amplitude loading, presented in this paper, consists of the following steps.

- Investigation of static strength evolution under cyclic loading (e.g. see Eq. (8)).

- Conducting typical fatigue tests under constant amplitude loading.

- Calibrating GUFD function by taking into account static strength evolution along with Eq. (9) $(D=1$ denotes fatigue destruction of the sample). In this paper polynomial form of the GUFD function were proposed Eq. (3) and (7).

- Predicting the fatigue life under variable amplitude loading by using the same formula Eq. (9) along with GUFD functions calibrated under constant amplitude loading. 